\title{
Three-dimensional quantitative assessment of surgical stability and condylar displacement changes after counterclockwise maxillomandibular advancement surgery: Effect of simultaneous articular disc repositioning
}

\author{
Liliane Rosas Gomes, ${ }^{a}$ Lúcia Helena Soares Cevidanes, ${ }^{b}$ Marcelo Regis Gomes, ${ }^{c}$ \\ Antônio Carlos de Oliveira Ruellas, ${ }^{\mathrm{d}}$ Daniel Patrick Obelenis Ryan, ${ }^{\mathrm{e}}$ Beatriz Paniagua, ${ }^{\mathrm{f}}$ \\ Larry Miller Wolford, ${ }^{g}$ and João Roberto Gonçalves ${ }^{a}$ \\ Araraquara, São Paulo, Salvador, Bahia, and Rio de Janeiro, Rio de Janeiro, Brazil, Ann Arbor, Mich, San Antonio and Dallas, \\ Tex, and Chapel Hill, NC
}

\begin{abstract}
Introduction: In this study, we quantitatively assessed 3-dimensional condylar displacement during counterclockwise maxillomandibular advancement surgery (CMMA) with or without articular disc repositioning, focusing on surgical stability in the follow-up period. Methods: The 79 patients treated with CMMA had cone-beam computed tomography scans taken before surgery, immediately after surgery, and, on average, 15 months postsurgery. We divided the 142 condyles into 3 groups: group $1(n=105)$, condyles of patients diagnosed with symptomatic presurgical temporomandibular joint articular disc displacement who had articular disc repositioning concomitantly with CMMA; group $2(n=23)$, condyles of patients with clinical verification of presurgical articular disc displacement who had only CMMA; and group $3(n=14)$, condyles of patients with healthy temporomandibular joints who had CMMA. Presurgical and postsurgical 3-dimensional models were superimposed using voxel-based registration on the cranial base. Three-dimensional cephalometrics and shape correspondence were applied to assess surgical and postsurgical displacement changes. Results: Immediately after surgery, the condyles moved mostly backward and medially and experienced lateral yaw, medial roll, and upward pitch in the 3 groups. Condyles in group 1 showed downward displacement, whereas the condyles moved upward in groups 2 and $3(P \leq 0.001)$. Although condylar displacement changes occurred in the 3 groups, the overall surgical procedure appeared to be fairly stable, particularly for groups 1 and 3 . Group 2 had the greatest amount of relapse $(P \leq 0.05)$. Conclusions: CMMA has been shown to be a stable procedure for patients with healthy temporomandibular joints and for those who had simultaneous articular disc repositioning surgery. (Am J Orthod Dentofacial Orthop 2018;154:221-33)
\end{abstract}

\footnotetext{
ounterclockwise maxillomandibular advancement surgery (CMMA) has often been used to treat hyperdivergent skeletal Class 11 patients. This

a Department of Orthodontics and Pediatric Dentistry, Araraquara School of Dentistry, São Paulo State University, Araraquara, São Paulo, Brazil.

${ }^{\mathrm{b}}$ Department of Orthodontics and Pediatric Dentistry, School of Dentistry, University of Michigan, Ann Arbor.

'Private practice, Salvador, Bahia, Brazil.

${ }^{\mathrm{d} D e p a r t m e n t}$ of Orthodontics, School of Dentistry, Federal University of Rio de Janeiro, Rio de Janeiro, Brazil.

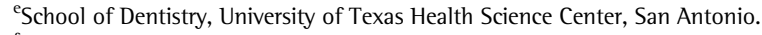
${ }^{f}$ Department of Psychiatry, School of Medicine, University of North Carolina, Chapel Hill.

${ }^{g}$ Department of Oral and Maxillofacial Surgery, Texas A\&tM University College of Dentistry, Baylor University Medical Center, Dallas.
}

surgical technique was developed as an effective means to achieve optimal functional and esthetic outcomes in patients with high occlusal plane facial deformities. ${ }^{1,2}$

All authors have completed and submitted the ICMJE Form for Disclosure of Potential Conflicts of Interest, and none were reported.

Supported by the National Institute of Dental \& Craniofacial Research of the National Institutes of Health (number R01DE024450) of the United States and the Säo Paulo Research Foundation (grant number 2013/22417-0) of Brazil.

Address correspondence to: Liliane Rosas Gomes, Universidade Estadual Paulista, Faculdade de Odontologia de Araraquara, Departamento de Clínica Infantil, Rua Humaitá, 1680, Araraquara, São Paulo, Brazil, CEP: 14801-903; e-mail, lilianerosas@hotmail.com.

Submitted, January 2017; revised and accepted, October 2017.

$0889-5406 / \$ 36.00$

(C) 2018 by the American Association of Orthodontists. All rights reserved.

https://doi.org/10.1016/j.ajodo.2017.10.030 
However, skeletal relapse after that orthognathic surgery has been a major issue because of problems related to the stretching of suprahyoid, pterygoid, and masseter muscles, as well as adverse effects on the temporomandibular joints (TMJs). ${ }^{1-3}$ Clinical concerns have been raised regarding the influence of suboptimal intraoperative positioning of the proximal segments: ie, condylar torque, which may be associated with progressive condylar resorption ${ }^{4-6}$ and subsequent postoperative relapse. ${ }^{7}$

CMMA has been described as a stable procedure for patients with healthy TMJs. ${ }^{8}$ However, controversial opinions surround the appropriate treatment plan for those with preexisting TMJ disorders who need such orthognathic surgery for correcting jaw deformities and malocclusions. ${ }^{8,9}$

Some authors have suggested that orthognathic surgery alone may reduce or eliminate TMJ dysfunction and symptoms, ${ }^{10,11}$ whereas others have reported damaging effects to the condyles from such surgery when there is internal derangement of the TMJs. ${ }^{12,13}$ For instance, after mandibular advancement, it may happen from muscular activity, which causes the discs to remain displaced as the condyles assume a superoposterior position in the fossae by an increase in mechanical loading. ${ }^{8,9}$

Some studies have shown that concomitant surgical correction of dentofacial deformities and TMJ disorders by repositioning and stabilizing the articular disc using the Mitek anchor technique (Mitek Products, Westwood, Mass) provides great treatment outcomes for most patients concerning functional, esthetic, and psychological aspects. ${ }^{8,14,15}$ Contrariwise, specific condylar displacement changes during articular disc repositioning surgery might be investigated as potential factors inducing condylar remodeling in the long-term follow-up, because of the condylar loading alteration. ${ }^{16}$ The current literature is still not clear about the best treatment option for preventing degenerative condylar changes after bimaxillary surgical advancement. ${ }^{15}$

Cone-beam computed tomography (CBCT) has been used for assessing condylar changes and surgical relapse. However, most previous studies have measured longitudinal changes by using 2-dimensional tools, which are susceptible to errors in determining corresponding landmark positions when bone remodeling occurs. Accurate quantitative 3-dimensional (3D) image techniques are now available, giving clinicians a new imaging modality to evaluate postoperative skeletal relapse as well as positional and dimensional condylar changes. ${ }^{7,15,17-19}$

The aim of this study was to quantitatively assess 3D condylar displacement changes during CMMA with or
Table I. Definition of landmarks used for 3D cephalometric analysis

\begin{tabular}{|c|c|c|}
\hline $\begin{array}{l}\text { Anatomic } \\
\text { landmark }\end{array}$ & Symbol & Definition \\
\hline Nasion & N & $\begin{array}{l}\text { Anterior point on the frontonasal } \\
\text { suture in the midsagittal plane }\end{array}$ \\
\hline Sella & S & $\begin{array}{l}\text { Midpoint at the posterior wall of sella } \\
\text { turcica, obtained by projection of } \\
\text { the geometric center of sella } \\
\text { passing through nasion }\end{array}$ \\
\hline Subspinale & A & $\begin{array}{l}\text { Deepest point on the anterior contour } \\
\text { of the maxillary alveolar process in } \\
\text { the midsagittal plane }\end{array}$ \\
\hline Supramentale & B & $\begin{array}{l}\text { Deepest point on the anterior contour } \\
\text { of the mandibular alveolar process } \\
\text { in the midsagittal plane }\end{array}$ \\
\hline Menton & Me & $\begin{array}{l}\text { Lowest point on the lower border of } \\
\text { the mandibular symphysis in the } \\
\text { midsagittal plane }\end{array}$ \\
\hline Gonion & Go & $\begin{array}{l}\text { Midpoint at the angle of the mandible, } \\
\text { obtained by the mean distance } \\
\text { between the right and left sides }\end{array}$ \\
\hline
\end{tabular}

without articular disc repositioning, focusing on surgical stability in the follow-up period.

\section{MATERIAL AND METHODS}

This retrospective study sample was composed of CBCT scans and clinical records from patients who had CMMA by the same surgeon (L.M.W.). Inclusion criteria were (1) osteotomies performed and stabilized with rigid internal fixation; (2) female patients at least 15 years old and male patients at least 17 years old; (3) patients with no TMJ abnormalities and with TMJ disc displacement assessed in clinical examinations and on magnetic resonance imaging interpreted by 2 experienced and calibrated doctors (L.M.W. and J.R.G.); and (4) CBCT scans acquired at 3 time points: before surgery (T1), immediately after surgery (T2), and at least 6 months postsurgery (T3). The exclusion criteria were patients with (1) craniofacial syndromes, (2) systemic degenerative conditions, (3) severe facial asymmetry, (4) previous TMJ surgery, and (5) previous arthroscopy, arthrocentesis, or viscosupplementation.

Records from 226 subjects consecutively treated from October 2008 to January 2011 were evaluated. One hundred nine patients were excluded for having undergone total prostheses of the TMJ. Thirty-eight patients were excluded for not having CBCT scans at all 3 time points (12 had TMJ articular disc repositioning surgery using the Mitek anchor technique (Mitek Products, Westwood, Mass), ${ }^{14}$ and the other 26 had no TMJ intervention). Therefore, 79 patients matched the inclusion criteria for this study. 


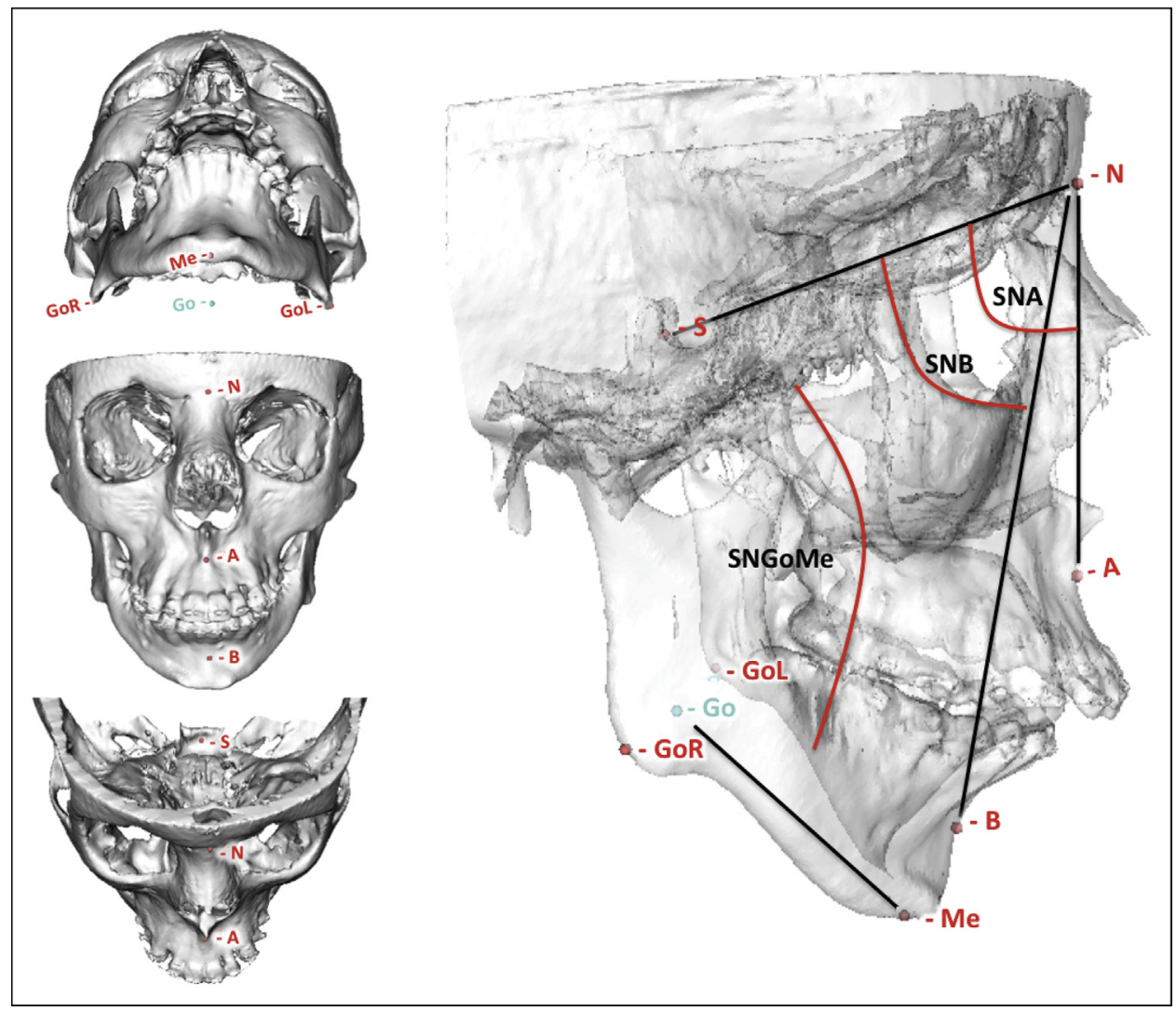

Fig 1. Three-dimensional cephalometric analysis.

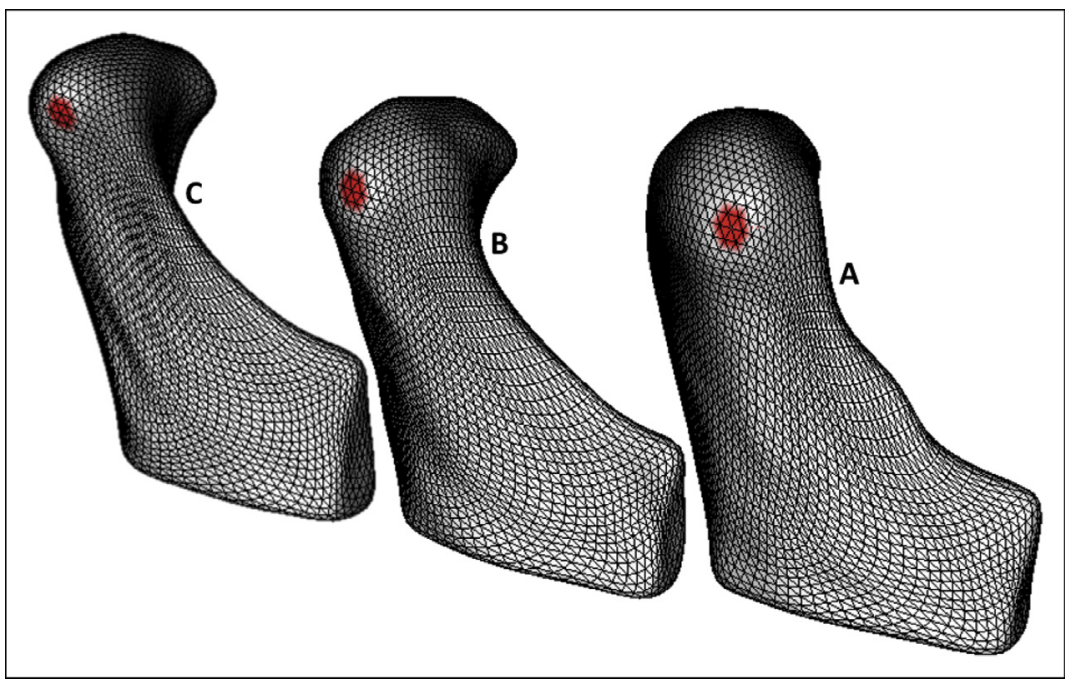

Fig 2. Example of lateral pole propagation considering correspondent surface mesh points: A, T1; B, T2; C, T3.

A total of 158 condyles were analyzed; 16 condyles were excluded due to previous arthroplasty. The final sample included 142 condyles divided into 3 groups: group $1(\mathrm{n}=105)$, condyles of patients diagnosed with symptomatic presurgical TMJ articular disc displacement who underwent articular disc repositioning 


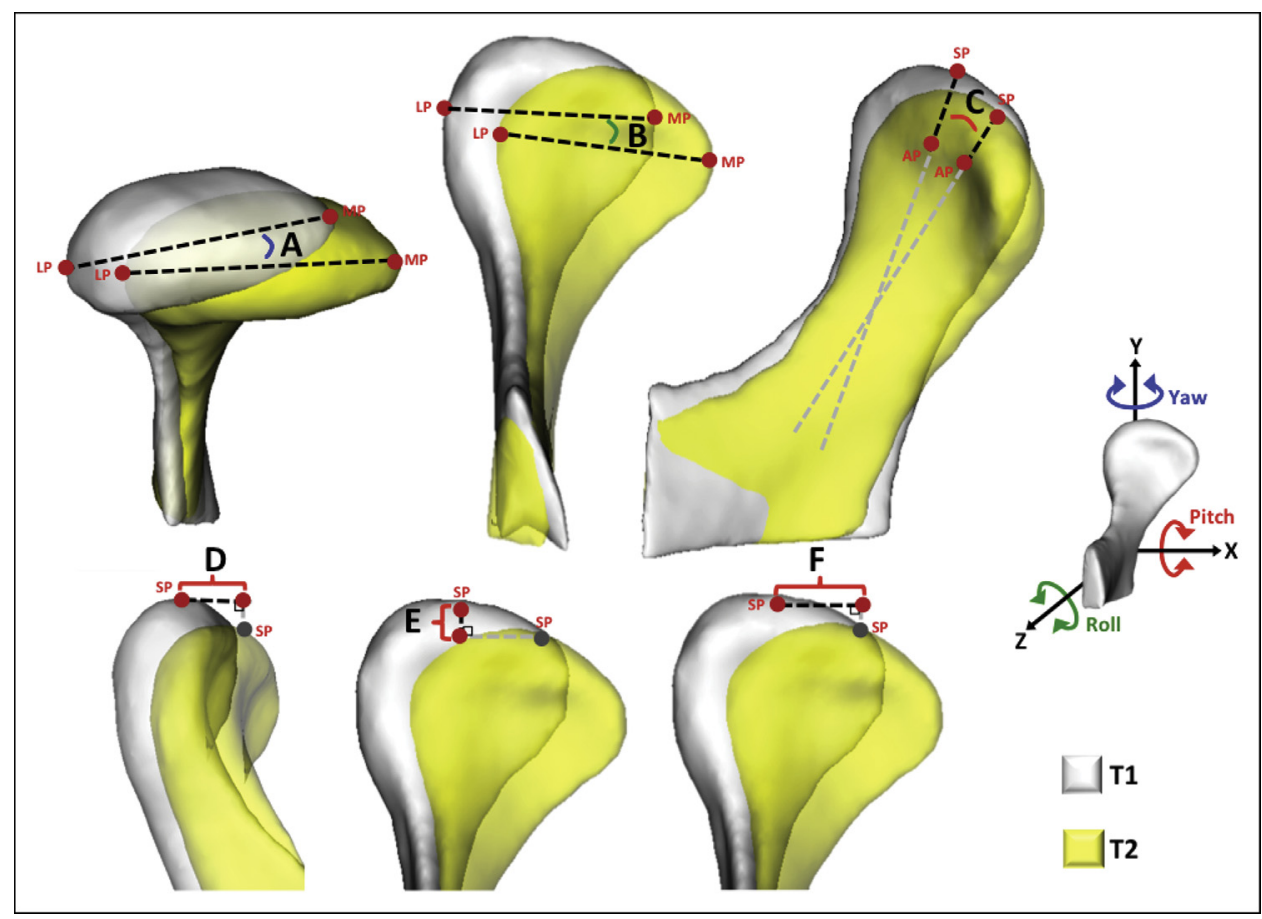

Fig 3. Rotational and translational measurements used to assess condylar changes; $\mathbf{A}$, yaw, rotation around the y-axis (axial view); B, roll, rotation around the z-axis (coronal view); C, pitch, rotation around the x-axis (sagittal view); D, anteroposterior displacement (sagittal view); E, vertical displacement (coronal view); $\mathbf{F}$, lateral displacement (coronal view).

\section{Table II. Direction of translational and rotational condylar displacement changes}

\begin{tabular}{|c|c|c|c|}
\hline Condylar displacement & Orthogonal view planes & Negative values & Positive values \\
\hline \multicolumn{4}{|l|}{ Translational changes } \\
\hline Anteroposterior* & Sagittal and axial & Anterior translation & Posterior translation \\
\hline Vertical $^{*}$ & Sagittal and coronal & Upward translation & Downward translation \\
\hline Lateral* & Coronal and axial & Lateral translation & Medial translation \\
\hline \multicolumn{4}{|l|}{ Rotational changes } \\
\hline Yaw & Axial & $\begin{array}{l}\text { Posterior rotation of the medial pole } \\
\text { and/or anterior rotation of the } \\
\text { lateral pole (medial yaw) }\end{array}$ & $\begin{array}{l}\text { Anterior rotation of the medial pole } \\
\text { and/or posterior rotation of the } \\
\text { lateral pole (lateral yaw) }\end{array}$ \\
\hline Roll & Coronal & Medial rotation & Lateral rotation \\
\hline Pitch & Sagittal & $\begin{array}{l}\text { Counterclockwise rotation (upward } \\
\text { pitch) }\end{array}$ & Clockwise rotation (downward pitch) \\
\hline
\end{tabular}

*Displacement.

concomitantly with CMMA. Many condyles in this group had osteoarthritis, showing severe flattening of the condylar surface, subchondral cysts, erosions, and osteophytes, causing considerable deformation of the condylar structure. In group $2(n=23)$, the condyles were of patients with clinical verification of presurgical bilateral TMJ articular disc displacement, mostly without osteoarthritic signs or symptoms, who underwent only CMMA. In group $3(\mathrm{n}=14)$, the condyles were of patients with healthy TMJs who had CMMA. All patients signed an informed consent form for hospital admission, surgical procedures, and release of information for research purposes. This study was approved by the institutional review board of the University of Michigan and complied with the Helsinki Declaration.

If indicated, articular disc repositioning surgery was performed using the Mitek anchor technique. ${ }^{14}$ This is an open-joint procedure performed simultaneously 
with the orthognathic surgery. Only salvageable discs were indicated for this surgery. A modified endaural incision was used to access the TMJ. The superior joint space was entered by incising the capsular ligaments, and the inferior joint space was entered with an incision just above the lateral pole of the condyle. The hyperplasic bilaminar tissue was wedge resected. The disc was mobilized and passively positioned over the condyle, with the lateral pterygoid muscle attachment preserved. The Mitek anchor with two 0 Ethibond sutures (Ethicon, Somerville, NJ) attached was inserted in the posterolateral surface of the condylar head, approximately $8 \mathrm{~mm}$ below the condylar top. The Ethibond sutures were attached to the posterior aspect of the posterior band of the disc for stabilization. The joint was then irrigated and the incision closed. ${ }^{14}$

After the TMJ surgery, the orthognathic surgery was performed. Counterclockwise rotation and advancement of the maxillomandibular complex was routinely performed on these patients that included bilateral mandibular ramus osteotomies and multiple maxillary (LeFort 1) osteotomies. Bilateral mandibular ramus sagittal split osteotomies were performed; the mandible was placed into its final position with an intermediate splint and intermaxillary fixation, and internal rigid fixation using bone plates and screws. Maxillary osteotomies were then performed, internasal procedures were completed if indicated, a palatal splint was inserted, intermaxillary fixation was placed, and rigid fixation was applied using 4 bone plates fixated with $2.0-\mathrm{mm}$ diameter screws.

The protocol for image acquisition was carried out with the patients sitting upright, keeping the Frankfort horizontal plane (trago-infraorbital) parallel to the ground. The mandible was positioned in centric relationship with the lips relaxed, and the patients were instructed not to swallow. CBCT images were obtained in the same machine (i-CAT CBCT, $120 \mathrm{kV}, 5 \mathrm{~mA}$; lmaging Sciences International, Hatfield, Pa) using a $17 \times 23-\mathrm{cm}$ extended field of view protocol, during a 17.8-second scan, with a $0.3-\mathrm{mm}$ isotropic voxel size. Records were taken 1 day (range, 1-2 days) before the surgery (T1), 5 days (range, 3-9 days) after surgery (T2), and in the longest follow-up (T3), on average, 15.4 months after surgery (range, 6-52 months). ${ }^{20}$

The CBCT images were reformatted to $0.5-\mathrm{mm}$ isotropic voxel size for the segmentation of the anatomic structures of interest. Three-dimensional models of the cranial base, maxilla, and mandible were constructed by outlining the cortical threshold using a semiautomatic procedure (ITK-SNAP software; www.itksnap.org).

The ITK-SNAP software was also used for cropping the cranial base model. This model indicated the registration program (CMF registration, 3DSlicer), the specific
Table III. Intraclass correlation coefficient values for intraobserver and interobserver reproducibility of the 3D cephalometric analysis

\begin{tabular}{lccc} 
& SNA & SNB & SN.GoMe \\
\hline Intraobserver reliability & & & \\
\hline Examiner 1, ICC & 0.97 & 0.95 & 0.98 \\
$\quad$ Examiner 2, ICC & 0.99 & 0.98 & 0.97 \\
Interobserver reliability & & & \\
$\quad$ ICC & 0.91 & 0.93 & 0.90 \\
\end{tabular}

place where we wanted the different time-point models to be superimposed. The cranial base was used as the reference for registration because it remains stable over time and does not change with surgical treatment. By using an automated voxel-wise rigid registration method that allowed 6 degrees of freedom, the program compared and matched different time point images considering the intensities of the voxel grey scales at the cranial base. ${ }^{18}$

Three-dimensional cephalometric analysis was used to determine the facial skeletal pattern before surgery and to assess the surgical changes (T1-T2) and postsurgical stability (T2-T3) (Q3DC, 3DSlicer). First, landmarks were positioned in specific places in the cranium as described in Table 1. Then the software automatically calculated the SNA and SNB angles to express the anteroposterior positions of the maxilla and mandible, respectively, relative to the cranial base. The SN.GoMe angle was also calculated to show the mandibular plane inclination (Fig 1).

For analyzing specific mandibular condylar displacement changes, superimposed models were simultaneously cropped (Easy Clip, 3DSlicer). All left condyles were mirrored in the sagittal plane to form right condyles. Then condylar models were compared by subtraction to compute the surgical (T1-T2) and postsurgical (T2-T3) changes by using the shape correspondence analysis (SPHARM-PDM, 3DSlicer). ${ }^{19}$

A mesh with 4002 correspondent points was generated by the shape correspondence analysis via spherical mapping and parameterization of each volume. 3DSlicer tool was then used to calculate the 3D point-wise linear distances between each time-point model (model to model distance, 3DSlicer).

Semitransparent overlays and vector maps were used to visually compare condylar displacement changes. The magnitudes of the computed 4002 differences were displayed on the condyle surface, and vector images pointed out the direction of the change.

Shape correspondence made it possible to mark the interest regions in 1 condyle alone (at T1) and propagate such regions for the other surgical time points (T2 and 
Table IV. Intraclass correlation coefficient values for intraobserver and interobserver reproducibility of condylar displacement changes

\begin{tabular}{lcccccc} 
& Anteroposterior & Vertical & Lateral & Yaw & Roll & Pitch \\
Intraobserver reliability & & & & & 0.99 & 0.99 \\
$\quad$ Examiner 1, ICC & 0.96 & 0.99 & 0.97 & 0.99 & 0.99 \\
$\quad$ Examiner 2, ICC & 0.85 & 0.99 & 0.96 & 0.99 & 0.82 \\
Interobserver reliability & 0.81 & 0.99 & 0.97 & 0.99 & 0.97 & 0.76 \\
\hline ICC & & & & &
\end{tabular}

\section{Table V. Demographic data before surgery (T1)}

Age (y) Follow-up (mo)

105 condyles from 57 patients (75 from female and 30 from male subjects)

\begin{tabular}{|c|c|c|c|c|c|}
\hline Mean & 27.3 & 16.8 & 40.7 & 79.1 & 74.6 \\
\hline SD & 12.2 & 8.6 & 7.4 & 3.7 & 4.3 \\
\hline Minimum & 16.0 & 6.0 & 25.1 & 69.5 & 59.4 \\
\hline Maximum & 58.0 & 52.0 & 61.0 & 87.0 & 83.0 \\
\hline \multicolumn{6}{|l|}{ Percentile } \\
\hline 15th & 16.0 & 9.6 & 32.9 & 75.2 & 71.1 \\
\hline 85th & 46.0 & 25.4 & 48.6 & 82.9 & 78.6 \\
\hline
\end{tabular}

Group 2

23 condyles from 15 patients ( 14 from female and 9 from male subjects)

\begin{tabular}{|c|c|c|c|c|c|}
\hline Mean & 29.7 & 14.7 & 39.6 & 79.9 & 76.6 \\
\hline SD & 10.8 & 7.7 & 4.5 & 3.6 & 3.1 \\
\hline Minimum & 15.0 & 7.0 & 29.1 & 72.7 & 69.6 \\
\hline Maximum & 46.0 & 39.0 & 47.4 & 85.5 & 81.6 \\
\hline \multicolumn{6}{|l|}{ Percentile } \\
\hline 15 th & 17.3 & 11.0 & 36.3 & 76.8 & 73.5 \\
\hline 85th & 41.0 & 21.4 & 44.0 & 84.9 & 79.4 \\
\hline \multicolumn{6}{|l|}{ Group 3} \\
\hline \multicolumn{6}{|c|}{14 condyles from 7 patients ( 6 from female and 8 from male subjects) } \\
\hline Mean & 33.3 & 14.7 & 41.7 & 80.0 & 78.0 \\
\hline SD & 17.4 & 7.7 & 7.2 & 6.9 & 5.0 \\
\hline Minimum & 15.0 & 8.0 & 28.8 & 67.7 & 71.7 \\
\hline Maximum & 63.0 & 31.0 & 49.3 & 90.4 & 86.1 \\
\hline \multicolumn{6}{|l|}{ Percentile } \\
\hline 15 th & 18.8 & 8.0 & 34.6 & 75.8 & 72.1 \\
\hline 85th & 48.8 & 17.7 & 47.4 & 85.2 & 82.1 \\
\hline
\end{tabular}

SNGoMe, Sella-nasion to mandibular plane angle; $S N A$, sella-nasion to A-point angle; $S N B$, sella-nasion to B-point angle.

Table VI. Descriptive statistics and Kruskal-Wallis test for comparing surgical displacement (T1-T2) changes

\begin{tabular}{|c|c|c|c|c|c|c|c|c|c|c|c|c|c|c|c|c|}
\hline \multirow{2}{*}{$\begin{array}{l}\text { Surgical } \\
\text { change* } \\
\text { (T1-T2) }\end{array}$} & \multicolumn{5}{|c|}{ Group 1} & \multicolumn{5}{|c|}{ Group 2} & \multicolumn{5}{|c|}{ Group 3} & \multirow[b]{2}{*}{ P value } \\
\hline & Mean & $S D$ & Med & Min & $\operatorname{Max}$ & Mean & $S D$ & Med & Min & $\operatorname{Max}$ & Mean & $S D$ & Med & Min & $\operatorname{Max}$ & \\
\hline SNGoMe ( $\left.{ }^{\circ}\right)$ & 5.9 & 3.4 & 5.25 & 0.7 & 14.6 & 5.2 & 2.7 & 5.1 & 1.5 & 11.2 & 5.4 & 3.0 & 6.6 & 1.5 & 9.0 & 0.772 \\
\hline $\operatorname{SNA}\left({ }^{\circ}\right)$ & -3.7 & 2.2 & -3.6 & -8.0 & 1.2 & -4.2 & 2.4 & -5.1 & -7.9 & -0.4 & -3.2 & 2.2 & -3.6 & -6.0 & 1.3 & 0.545 \\
\hline SNB $\left(^{\circ}\right)$ & -6.0 & 2.3 & -6.0 & -12.6 & -0.6 & -5.4 & 1.9 & -5.2 & -8.3 & -0.3 & -3.9 & 2.0 & -4.2 & -6.7 & -0.2 & 0.002 \\
\hline
\end{tabular}

Significant at $P \leq 0.05$.

Med, Median; Min, minimum; Max, maximum; SNGoMe, sella-nasion to mandibular plane angle; SNA, sella-nasion to A-point angle; SNB, sellanasion to B-point angle.

*Positive values indicate counterclockwise rotation, and negative values indicate clockwise rotation for SNGoMe measurements; for SNA and SNB angles, negative values indicate that the maxilla or mandible moved anteriorly, and positive values indicate that it moved posteriorly. 
Table VII. Mann-Whitney post hoc comparisons of surgical displacements between groups

\begin{tabular}{|c|c|c|c|c|c|c|}
\hline \multirow[b]{2}{*}{ Surgical change (T1-T2) } & \multicolumn{2}{|c|}{ Group 1-group 2} & \multicolumn{2}{|c|}{ Group 1-group 3} & \multicolumn{2}{|c|}{ Group 2-group 3} \\
\hline & Mean difference & P value & Mean difference & $\mathrm{P}$ value & Mean difference & $\mathrm{P}$ value \\
\hline SNGoMe $\left({ }^{\circ}\right)$ & 0.7 & 0.454 & 0.5 & 0.888 & -0.2 & 0.875 \\
\hline $\operatorname{SNA}\left({ }^{\circ}\right)$ & 0.5 & 0.388 & -0.5 & 0.662 & -1.0 & 0.222 \\
\hline SNB $\left(^{\circ}\right)$ & -0.6 & 0.166 & -2.1 & 0.001 & -1.5 & 0.036 \\
\hline
\end{tabular}

SNGoMe, Sella-nasion to mandibular plane angle; $S N A$, sella-nasion to A-point angle; $S N B$, sella-nasion to B-point angle.

Significant at $P \leq 0.05$.

Table VIII. Descriptive statistics and 1-way analysis of variance for comparing condylar linear and rotational displacements during surgery (T1-T2)

\begin{tabular}{|c|c|c|c|c|c|c|c|c|c|c|c|c|c|c|c|c|}
\hline \multirow{2}{*}{$\begin{array}{l}\text { Condylar } \\
\text { displacement* } \\
(T 1-T 2)\end{array}$} & \multicolumn{5}{|c|}{ Group $1(n=105)$} & \multicolumn{5}{|c|}{ Group $2(n=23)$} & \multicolumn{5}{|c|}{ Group $3(n=14)$} & \multirow[b]{2}{*}{$\mathrm{P}$ value } \\
\hline & Mean & $S D$ & Med & Min & Max & Mean & $S D$ & Med & Min & $\operatorname{Max}$ & Mean & $S D$ & Med & Min & $\operatorname{Max}$ & \\
\hline $\mathrm{AP}(\mathrm{mm})$ & 0.6 & 1.2 & 0.6 & -3.2 & 3.5 & 0.7 & 0.7 & 0.6 & -1.0 & 2.4 & 0.9 & 1.1 & 0.7 & -0.4 & 3.2 & 0.523 \\
\hline Vert (mm) & 0.9 & 1.2 & 0.9 & -2.3 & 5.0 & -0.1 & 0.8 & -0.3 & -1.2 & 1.9 & -0.3 & 0.9 & -0.2 & -2.0 & 0.8 & 0.000 \\
\hline Late (mm) & 1.5 & 1.7 & 1.3 & -2.5 & 7.3 & 1.0 & 1.4 & 0.7 & -1.4 & 4.8 & 0.9 & 1.3 & 1.2 & -1.1 & 2.6 & 0.243 \\
\hline Yaw $\left(^{\circ}\right)$ & 4.0 & 5.5 & 3.6 & -11.8 & 18.3 & 3.2 & 5.1 & 3.0 & -10.6 & 12.1 & 3.8 & 5.1 & 2.9 & -5.0 & 11.6 & 0.797 \\
\hline Roll $\left({ }^{\circ}\right)$ & -5.5 & 6.6 & -5.3 & -30.5 & 8.7 & -2.4 & 5.4 & -1.6 & -13.5 & 6.1 & -0.3 & 5.3 & 0.3 & -12.3 & 8.9 & 0.005 \\
\hline Pitch $\left(^{\circ}\right)$ & -7.7 & 7.6 & -7.8 & -32.3 & 14.0 & -3.3 & 5.5 & -2.1 & -18.6 & 7.9 & -1.4 & 4.6 & -1.6 & -8.5 & 10.7 & 0.001 \\
\hline
\end{tabular}

Table IX. Hochberg GT2 post hoc comparisons of condylar linear and rotational displacements between groups

\begin{tabular}{|c|c|c|c|c|c|c|}
\hline \multirow[b]{2}{*}{ Condylar displacement (T1-T2) } & \multicolumn{2}{|c|}{ Group 1-group 2} & \multicolumn{2}{|c|}{ Group 1-group 3} & \multicolumn{2}{|c|}{ Group 2-group 3} \\
\hline & Mean difference & $\mathrm{P}$ value & Mean difference & $\mathrm{P}$ value & Mean difference & $\mathrm{P}$ value \\
\hline $\mathrm{AP}(\mathrm{mm})$ & -0.1 & 0.920 & -0.3 & 0.640 & -0.2 & 0.942 \\
\hline Vert (mm) & 1 & 0.000 & 1.2 & 0.001 & 0.2 & 0.975 \\
\hline Late (mm) & 0.5 & 0.448 & 0.6 & 0.542 & 0.1 & 1.000 \\
\hline Yaw $\left({ }^{\circ}\right)$ & 0.8 & 0.877 & 0.2 & 0.998 & -0.6 & 0.984 \\
\hline Roll $\left({ }^{\circ}\right)$ & -3.1 & 0.109 & -5.2 & 0.014 & -2.1 & 0.691 \\
\hline
\end{tabular}

Significant at $P \leq 0.05$.
$A P$, Anteroposterior displacement; Vert, vertical displacement; Late, lateral displacement; Yaw, rotation around the y-axis; Roll, rotation around $A P$, Anteroposterior displacement; Vert, vertical displacement; Late, lateral displacement; Yaw, rotation around the y-axis; Roll, rotation around
the z-axis; Pitch, rotation around the x-axis.

T3), obtaining $x, y$, and $z$ coordinates for each point (Pick 'n Paint module, 3DSlicer) (Fig 2). Then the Q3DC module in the 3D Slicer software allowed measuring both translational and rotational displacements (Fig 3). Positive or negative signs indicated displacement directions (Table 11).

\section{Statistical analysis}

The reliability of the 3D cephalometric analysis and condylar displacement changes were assessed by repeating landmark positioning and measurements on the CBCT images of 10 randomly selected subjects.
Two examiners (L.R.G., M.R.G.) were carefully calibrated. For intraobserver reproducibility, each examiner performed landmark positioning and measurements at 2 times, with an interval of at least 1 week between the assessments. For interobserver reproducibility, landmark positioning and measurements by each examiner were compared. We used the intraclass correlation coefficient (ICC). ${ }^{20}$

Kolmogorov-Smirnov and Shapiro-Wilk tests were used to check the normality of data distribution in each group. Descriptive statistics reported presurgical (T1), surgical (T1-T2), and postsurgical changes 


\section{Condylar displacement (T1-T2)}

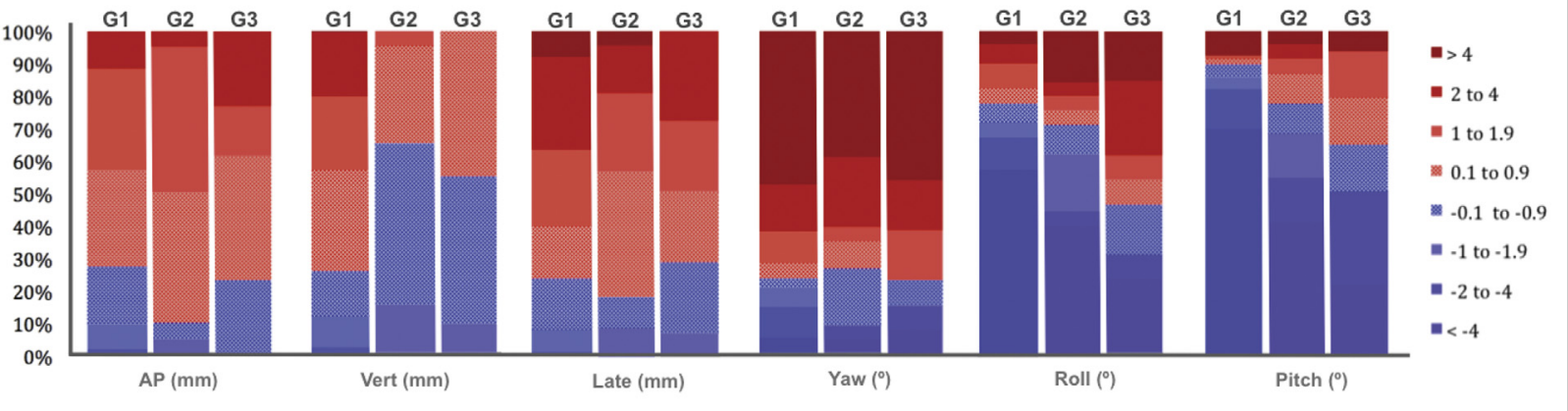

Fig 4. Percentages of condyles considering direction and magnitude of translational and rotational changes during surgery (T1-T2) in groups 1, 2, and 3. See Table II for detailed information regarding direction of each condylar displacement change. AP, Anteroposterior; G, Group; Vert, vertical; Late, lateral.

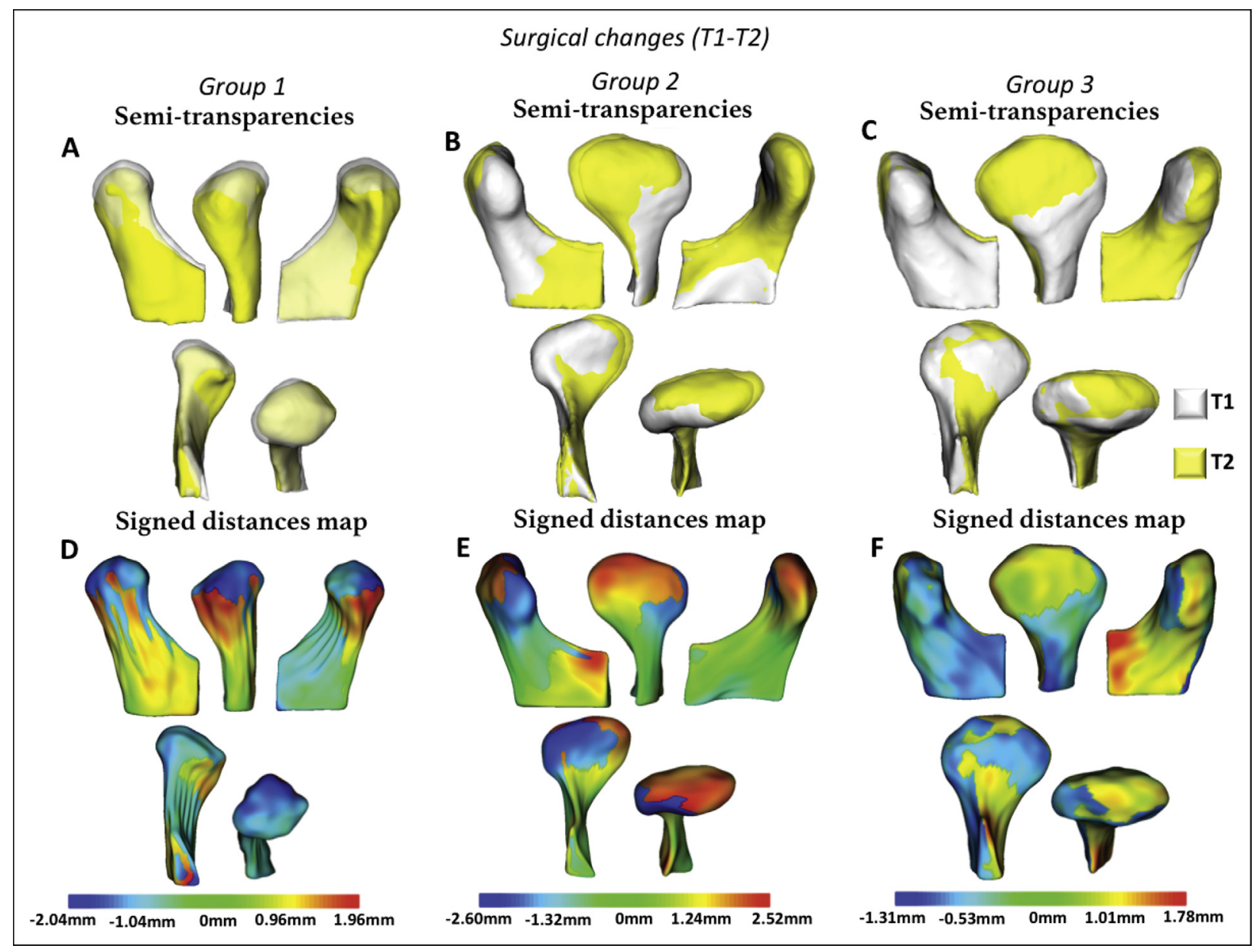

Fig 5. Right condyle models of randomly selected patients: $\mathbf{A}, \mathbf{B}$, and $\mathbf{C}$, semitransparent overlays showing condylar displacement during surgery; D, E, and F, respective color-coded signed distance maps. 


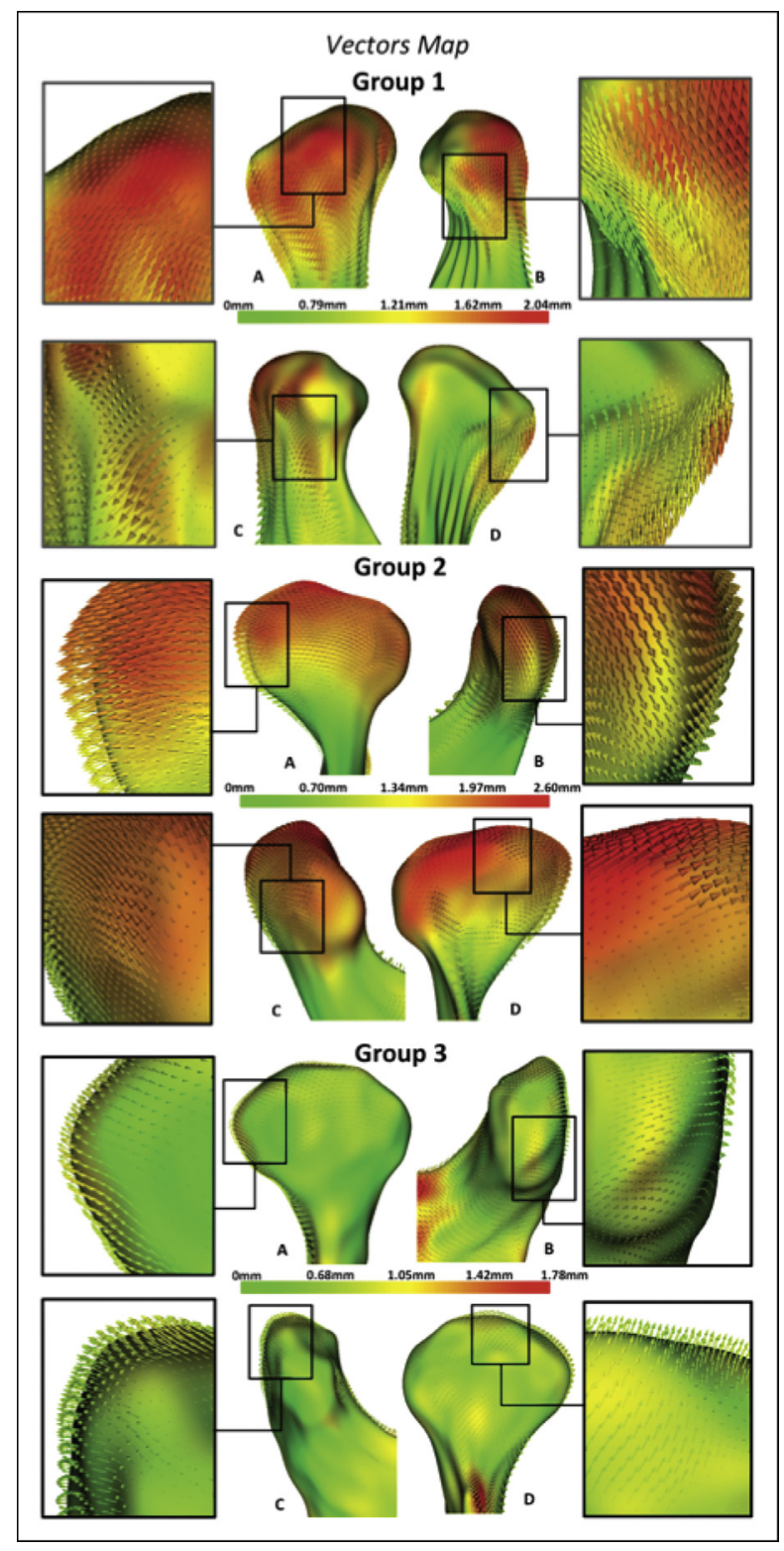

Fig 6. Vector map showing changes from $\mathrm{T} 1$ to $\mathrm{T} 2$ in randomly selected condyles: $\mathbf{A}$, posterior view; $\mathbf{B}$, medial view; C, lateral view; $\mathbf{D}$, anterior view.

(T2-T3) in each of the 3 groups. For normally distributed data, the differences among the groups were tested by using 1-way analysis of variance followed by the Hochberg GT2 post hoc test, appropriate for unequal sample sizes. For nonparametric data, the Kruskal-Wallis test compared the overall significance of the differences among the 3 groups, whereas the Mann-Whitney test compared 2 groups at a time (version 16.0; SPSS, Chicago, III). A significance level of $P \leq 0.05$ was applied.

\section{RESULTS}

Three-dimensional cephalometric analysis showed high intraobserver and interobserver reproducibilities for all diagnostic variables (ICC $\geq 0.9$ ) (Table 111). The method used to measure condylar displacement changes also showed high intraobserver and interobserver reproducibilities $(I C C \geq 0.8$ ) (Table IV). Demographic characteristics of the sample are listed in Table V. The 3 groups had similar mean ages, follow-up periods, and craniofacial patterns $(P \geq 0.05)$. The patients on average had high mandibular plane angles and bimaxillary retrusions.

The amounts of counterclockwise rotation and maxillary advancement were similar in the 3 groups. However, patients in groups 1 and 2 experienced greater mandibular advancement compared with group 3 $(P \leq 0.01)$ (Tables $\mathrm{Vl}$ and $\mathrm{V} \mathrm{VI})$.

For condylar translational changes during surgery, it was observed that, on average, the condyles moved backward and medially in the 3 groups. Patients having disc repositioning surgery (group 1) showed, on average, downward condylar displacement, whereas the condyle moved upward in groups 2 and $3(P \leq 0.001)$.

Regarding mean condylar rotational changes, lateral yaw, medial roll, and upward pitch were observed in the 3 groups. However, group 1 showed a greater upward pitch compared with group $2(P \leq 0.05)$ and group 3 $(P \leq 0.01)$. Medial roll was also significantly larger in group 1 relative to group $3(P \leq 0.01)$ (Tables VIII and IX).

In general, the averages obtained reflected the most prevalent displacement directions in each group. For instance, at least $70 \%$ of the sample in group 1 experienced backward, downward, and medial displacements, as well as lateral yaw, medial roll, and upward pitch. The other condyles moved in the opposite direction. Condylar translational changes were less than $2 \mathrm{~mm}$ for most of the subjects in the 3 groups. However, greater rotational changes were observed. Figure 4 gives a detailed description of the percentages of condylar displacement changes in each group.

Semitransparencies and signed-distance color-coded maps illustrating the displacements are presented in Figure 5. The distances shown in the maps were determined by subtracting each of the 4002 corresponding surface points between the $\mathrm{T} 1$ and $\mathrm{T} 2$ models. Figure 6 illustrates condylar displacements in vector maps.

We observed no statistically significant differences between groups 1 and 3 for postsurgical stability. Mean relapses in counterclockwise rotation, and maxillary and mandibular advancement were quite small ( $\leq 0.9 \mathrm{in}$ ) in these groups (Tables X and XI; Fig 7). Group 
Table X. Descriptive statistics and group comparisons relative to postsurgical stability (T2-T3)

\begin{tabular}{|c|c|c|c|c|c|c|c|c|c|c|c|c|c|c|c|c|}
\hline \multirow{2}{*}{$\begin{array}{l}\text { Post-surgical } \\
\text { change* } \\
\text { (T2-T3) }\end{array}$} & \multicolumn{5}{|c|}{ Group 1} & \multicolumn{5}{|c|}{ Group 2} & \multicolumn{5}{|c|}{ Group 3} & \multirow[b]{2}{*}{$\mathrm{P}$ value } \\
\hline & Mean & $S D$ & Med & Min & Max & Mean & $S D$ & Med & Min & $\operatorname{Max}$ & Mean & $S D$ & Med & Min & Max & \\
\hline SNGoMe $\left({ }^{\circ}\right)$ & -0.9 & 1.0 & -0.8 & -4.5 & 2.3 & -1.0 & 1.0 & -1.0 & -3.0 & 0.8 & -0.9 & 0.3 & -0.8 & -1.4 & -0.4 & 0.872 \\
\hline SNA $\left(^{\circ}\right)$ & 0.9 & 0.7 & 0.9 & -1.0 & 3.1 & 0.6 & 0.7 & 0.6 & -0.5 & 2.0 & 0.7 & 0.5 & 0.5 & 0.2 & 1.6 & $0.566^{\dagger}$ \\
\hline SNB $\left(^{\circ}\right)$ & 0.2 & 1.0 & 0.2 & -1.7 & 3.2 & 1.0 & 1.1 & 0.8 & -0.7 & 3.2 & 0.1 & 0.4 & 0.0 & -0.3 & 0.7 & $0.031^{\ddagger}$ \\
\hline
\end{tabular}

Significant at $P \leq 0.05$.

Med, Median; Min, minimum; Max, maximum; SNGoMe, sella-nasion to mandibular plane angle; SNA, sella-nasion to A-point angle; SNB, sellanasion to B-point angle.

*Positive values indicate counterclockwise rotation, and negative values indicate clockwise rotation for SNGoMe measurements; for SNA and SNB angles, negative values indicate the maxilla or mandible moved anteriorly, and positive values indicate that it moved posteriorly; ${ }^{\dagger}$ Analysis of variance; ${ }^{\ddagger}$ Kruskal-Wallis.

Table XI. Post hoc comparisons of postsurgical stability (T2-T3) between groups

\begin{tabular}{|c|c|c|c|c|c|c|}
\hline \multirow[b]{2}{*}{ Postsurgical change (T2-T3) } & \multicolumn{2}{|c|}{ Group 1-group 2} & \multicolumn{2}{|c|}{ Group 1-group 3} & \multicolumn{2}{|c|}{ Group 2-group 3} \\
\hline & Mean difference & P value & Mean difference & P value & Mean difference & $\mathrm{P}$ value \\
\hline SNGoMe $\left(^{\circ}\right)$ & 1.0 & 0.872 & 0.9 & 1.000 & -0.1 & $0.957^{*}$ \\
\hline SNA $\left(^{\circ}\right)$ & 0.3 & 0.981 & 0.2 & 0.713 & -0.1 & $0.661^{*}$ \\
\hline SNB $\left(^{\circ}\right)$ & -0.8 & 0.014 & -0.1 & 0.824 & 0.9 & $0.012^{\dagger}$ \\
\hline
\end{tabular}

Significant at $P \leq 0.05$.

SNGoMe, sella-nasion to mandibular plane angle; SNA, sella-nasion to A-point angle; SNB, sella-nasion to B-point angle.

${ }^{*}$ Hochberg GT2 test; ${ }^{\dagger}$ Mann-Whitney test.

2 had the largest percentage of patients experiencing relapse greater than $1.0^{\circ}$ in SNGoMe, SNA, and SNB angles during the follow-up period. About $40 \%$ of the subjects in group 2 and 16\% in group 1 had a relapse greater than $1.0^{\circ}$ for the SNB angle. No patient in group 3 experienced relapse greater than $1.5^{\circ}$ in SNGoMe or greater than $1.0^{\circ}$ in SNB (Fig 8). Statistically significant differences were observed between groups 1 and 2 $(P \leq 0.05)$, and groups 3 and $2(P \leq 0.05)$ relative to the stability of the mandibular anteroposterior position (SNB angle) (Table XI).

\section{DISCUSSION}

Although CMMA provides great functional and esthetic results, postsurgical skeletal relapse is still a common phenomenon. We attributed this fact mainly to suboptimal positioning of the proximal segments during surgery, which may be associated with progressive condylar resorption. ${ }^{4-6}$ This study is the first to assess condylar spatial changes after CMMA and TMJ articular disc repositioning using shape correspondence analysis, which allows a unique and symmetric point-to-point correspondence across all measured surfaces.

The position and morphology of the disc has been shown to be closely related to the stress suffered by the joint. ${ }^{5}$ Gonçalves et $\mathrm{al}^{8}$ observed greater relapses in patients with preoperative disc displacement who had mandibular advancement without disc repositioning. However, controversies still exist regarding this open-joint procedure. ${ }^{8,9,14}$ A precisely performed TMJ disc repositioning surgery may give patients with presurgical TMJ disorders similar remodeling changes as those observed in patients with no history of TMJ problems. ${ }^{15}$ On the other hand, the procedure may aggravate the degenerative process if the fibrocartilage is negligently injured. ${ }^{15}$

Some authors have assumed that condylar resorption can occur regardless of the position of the disc, since condylar torque is the main etiologic factor. ${ }^{4-6}$ Contrariwise, Dicker et $\mathrm{al}^{21}$ suggested that neither postoperative joint loading increases nor condylar sagittal rotations are relevant causes of condylar resorption or surgical relapse. ${ }^{6}$

By using different methods, researchers have studied the condylar movements that occur in patients who have undergone orthognathic surgery. ${ }^{15,22,23}$ A usual finding is that both condyles move posteriorly after sagittal split ramus osteotomy to advance the mandible. ${ }^{15,22,23}$

In our study, it was observed that most condyles translated backward and medially in the 3 groups immediately after surgery. However, statistically significant differences among the groups were observed regarding vertical displacement. Patients in group 1 showed 


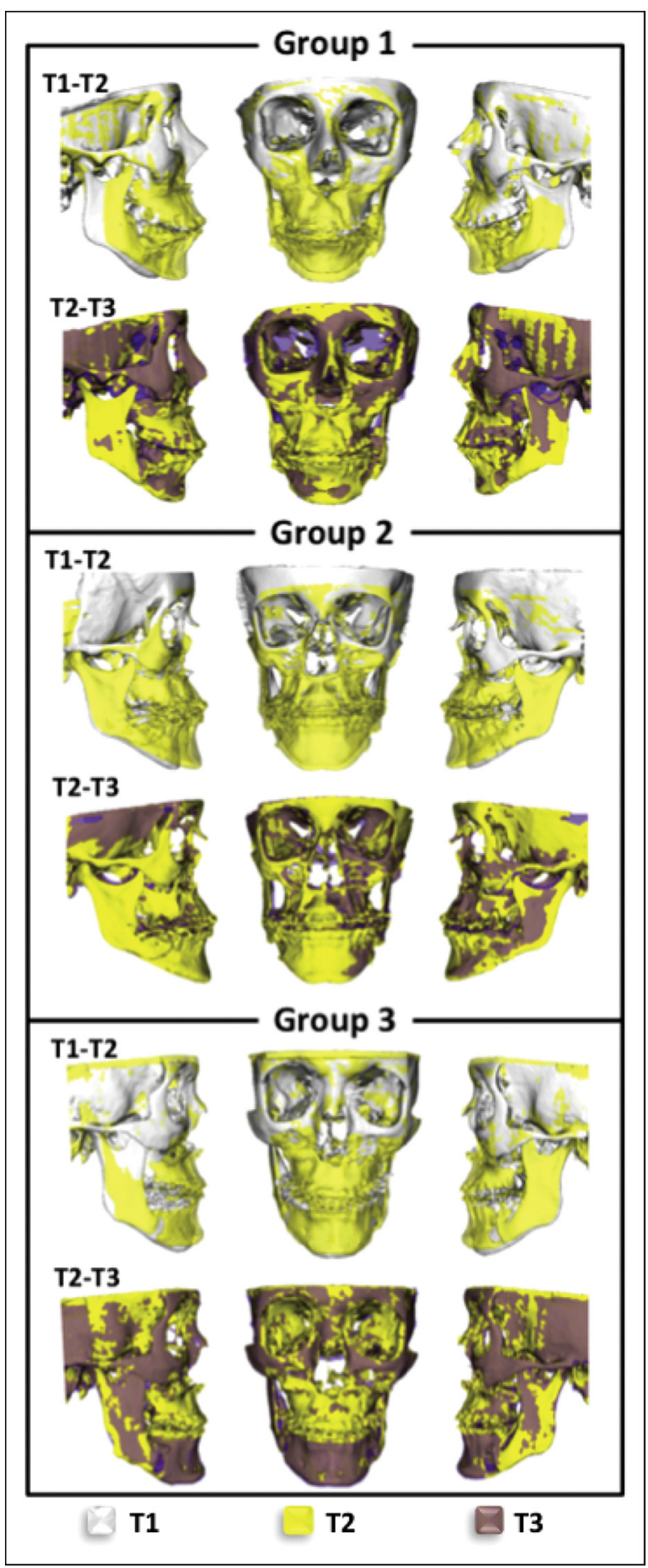

Fig 7. Semitransparent overlays showing overall surgical (T1-T2) and postsurgical (T2-T3) changes from randomly selected patients.

downward condylar displacement, whereas the condyle moved upward in groups 2 and 3. This difference would be expected because it is necessary to open space for the disc to be positioned back in place with the Mitek anchor, which is inserted at the upper lateral region of the condyle. ${ }^{15}$

Gonçalves et $\mathrm{al}^{15}$ observed that patients who had disc repositioning surgery showed downward condylar displacement, whereas the condyle moved upward when only maxillomandibular advancement was conducted; this corroborates our findings. However, we found that the condyles translated backward in patients treated with maxillomandibular advancement only, whereas the condyle moved forward in patients treated with simultaneous articular disc repositioning.

In this study, anteroposterior condylar displacement in group 1 ranged from -3.2 to $3.5 \mathrm{~mm}$; this means that the condyles in this group moved both backward and forward, with the backward displacement more prevalent (about $70 \%$ of the sample in group 1). Although, on average, the condyles translated backward, the real amount of condylar anteroposterior movement was small-less than $2 \mathrm{~mm}$ for about $90 \%$ of the sample.

Greater amounts of mandibular advancement and counterclockwise rotation were observed in group 1 ; these would generate greater condylar loading by stretching the submandibular soft tissues and muscles. ${ }^{6}$ However, the percentage of condyles showing backward displacement was about 10\% lower in this group compared with groups 2 and 3. This fact may confirm that disc repositioning surgery exerts some forward pressure that is not as strong as the downward pressure, but it can somehow compensate for part of the backward load.

Regarding condylar rotational changes immediately after surgery, lateral yaw, medial roll, and upward pitch were observed in the 3 groups. However, group 1 showed greater amounts of upward pitch and medial roll. Gonçalves et $\mathrm{al}^{15}$ also found that medial roll and lateral yaw occurred regardless of TMJ disc repositioning, but they noted similar amounts and frequencies between the groups.

Our findings for patients having CMMA corroborate those of previous studies, showing that condylar displacements and rotations after mandibular advancement result in posterosuperior displacements and medial condylar angulations, as assessed from CBCT images. $^{15,17}$

Although condylar displacements occurred, only a small percentage of the patients in the 3 groups experienced postsurgical relapses as measured by SNGoMe, $\mathrm{SNA}$, and SNB angles greater than $1.5^{\circ}$. Kim et $\mathrm{al}^{22}$ reported that condylar positional changes in all planes occurred without signs or symptoms of TMJ disorder, because of the individual capacity of physiologic adaptation. Such condylar changes did not seem to affect 


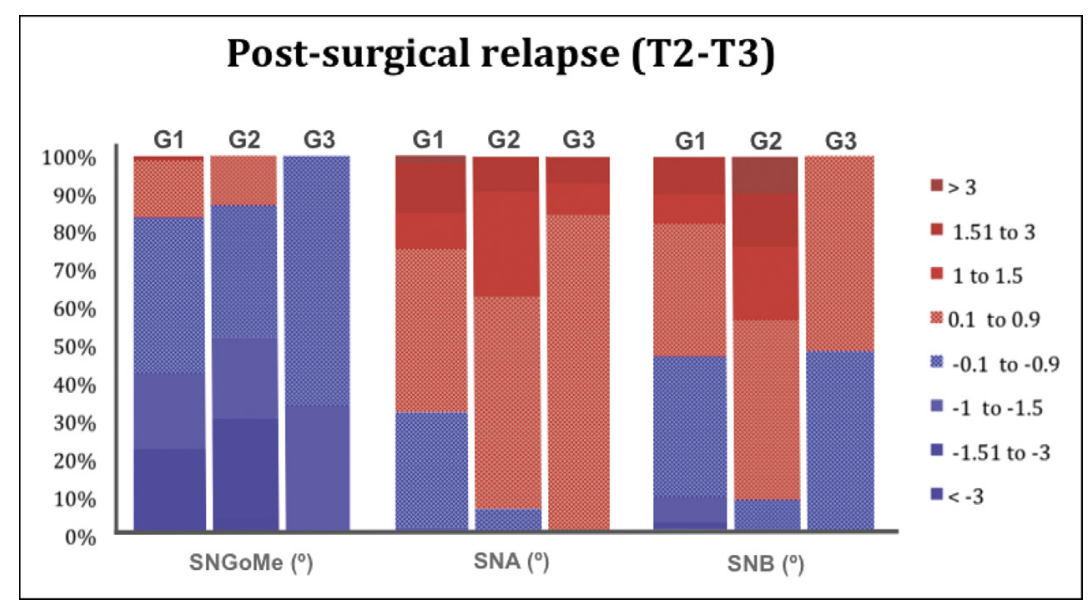

Fig 8. Percentages of patients according to postsurgical relapse (T2-T3) in groups 1,2 , and 3 . Positive values indicate counterclockwise rotation, and negative values indicate clockwise rotation for SNGoMe measurements. For SNA and SNB angles, negative values indicate that the maxilla or mandible moved anteriorly, and positive values indicate that it moved posteriorly. G, Group.

the long-term skeletal stability, which corroborates our findings. Other authors have also found that small condylar rotations do not appear to have a functional compromise. $^{23,24}$ However, the amount of condylar change that may be compatible with postsurgical normal function is still unknown. ${ }^{17}$

In this study, mean relapses in counterclockwise rotation, and maxillary and mandibular advancement, were in general quite small $\left(\leq 1.0^{\circ}\right)$. However, group 2 showed the largest postsurgical mean changes measured by the SNB and SNGoMe angles. The percentage of patients experiencing changes in SNGoMe, SNA, and SNB angles during the follow-up period was also the highest in group 2 . Statistically significant differences among the groups were observed for the SNB variable.

Kobayashi et al ${ }^{16}$ noted a higher incidence of progressive postoperative condylar resorption in hyperdivergent retrognathic patients with preoperative erosion, condyle deformity, or both. Therefore, patients in group 1 would be expected to show higher levels of skeletal relapse because they had symptomatic presurgical TMJ articular disc displacement. Many patients in this group showed condylar osteoarthritis, with severe flattening of the condylar surface, subchondral cysts, erosions, and osteophytes, generating considerable deformation of the condylar structure. Contrariwise, group 2 was composed of condyles from patients with clinical verification of presurgical bilateral TMJ articular disc displacement, mostly without osteoarthritic signs or symptoms.

It may be inferred that the articular disc repositioning surgery with the Mitek anchor technique gave patients with preoperative condylar osteoarthritic changes similar CMMA follow-up results from those obtained for patients with healthy TMJs, corroborating the findings of Gonçalves et al. ${ }^{15}$

Another important aspect to be addressed refers to the controversy that still surrounds the counterclockwise rotation of the maxillomandibular complex. Authors have stated that avoiding changes to the mandibular plane inclination contributed to postoperative surgical stability. ${ }^{3}$ A counterclockwise rotation of the proximal segments combined with a posterior inclination of the condylar neck would increase loading of the anteriorsuperior surface of the condyle, making it more prone to resorption with subsequent skeletal relapse. ${ }^{25}$

Although our sample, particularly group 1 , showed greater mandibular advancement (mean, 6.0 $0^{\circ}$ and counterclockwise rotation (mean, $5.9^{\circ}$ ) of the maxillomandibular complex than in previous reports, the mean surgical relapse was small. ${ }^{726}$ Therefore, CMMA has proven stability when preexisting TMJ pathology is identified and properly managed. ${ }^{1,2}$

Future 3D studies with larger samples of patients with healthy condyles or clinical verification of presurgical bilateral articular disc displacement and no TMJ intervention are needed to confirm the importance of performing disc replacement surgery with the Mitek anchor before CMMA.

\section{CONCLUSIONS}

1. Although condylar displacements occurred, the overall surgical procedure appeared to be fairly 
stable, particularly for groups 1 and 3. Group 2 had the greatest amount and percentage of patients experiencing relapse. Statistically significant differences were observed relative to the stability of mandibular anteroposterior position during the follow-up period.

2. Results from this study suggest that articular disc repositioning surgery with the Mitek anchor technique simultaneously with CMMA gives patients with preoperative condylar osteoarthritic changes better follow-up results from those obtained for patients with clinical verification of presurgical TMJ articular disc displacement who underwent CMMA without TMJ intervention.

3. CMMA seems to be a stable procedure in properly selected patients, when recognizing preexisting TMJ pathology and managing it appropriately. However, caution is still needed when recommending disc replacement surgery because of the smaller numbers of patients in groups 2 and 3 in this study. Future 3D studies with larger control samples are encouraged.

\section{REFERENCES}

1. Chemello PD, Wolford LM, Buschang PH. Occlusal plane alteration in orthognathic surgery-part 11: long-term stability of results. Am J Orthod Dentofacial Orthop 1994;106:434-40.

2. Al-Moraissi EA, Wolford LM. 1s counterclockwise rotation of the maxillomandibular complex stable compared with clockwise rotation in the correction of dentofacial deformities? A systematic review and meta-analysis. J Oral Maxillofac Surg 2016;74: 2066.e1-12.

3. Proffit WR, Turvey TA, Phillips C. The hierarchy of stability and predictability in orthognathic surgery with rigid fixation: an update and extension. Head Face Med 2007;3:21.

4. Arnett GW, Milam SB, Gottesman L. Progressive mandibular retrusion-idiopathic condylar resorption. Part 11. Am J Orthod Dentofacial Orthop 1996;110:117-27.

5. Ueki K, Moroi A, Sotobori M, 1shihara Y, Marukawa K, Takatsuka S, et al. A hypothesis on the desired postoperative position of the condyle in orthognathic surgery: a review. Oral Surg Oral Med Oral Pathol Oral Radiol 2012;114:567-76.

6. Xi T, de Koning M, Berge S, Hoppenreijs T, Maal T. The role of mandibular proximal segment rotations on skeletal relapse and condylar remodelling following bilateral sagittal split advancement osteotomies. J Craniomaxillofac Surg 2015;43:1716-22.

7. Xi T, Schreurs R, van Loon B, de Koning M, Bergé S, Hoppenreijs T, et al. 3D analysis of condylar remodelling and skeletal relapse following bilateral sagittal split advancement osteotomies. J Craniomaxillofac Surg 2015;43:462-8.

8. Goncalves JR, Cassano DS, Wolford LM, Santos-Pinto A, Marquez 1M. Postsurgical stability of counterclockwise maxillomandibular advancement surgery: affect of articular disc repositioning. J Oral Maxillofac Surg 2008;66:724-38.

9. Wolford LM, Reiche-Fischel 0, Mehra P. Changes in temporomandibular joint dysfunction after orthognathic surgery. J Oral Maxillofac Surg 2003;61:655-60.
10. Magnusson T, Ahlborg G, Finne K, Nethander G, Svartz K. Changes in temporomandibular joint pain-dysfunction after surgical correction of dentofacial anomalies. Int J Oral Maxillofac Surg 1986;15:707-14.

11. Panula K, Somppi M, Finne K, Oikarinen K. Effects of orthognathic surgery on temporomandibular joint dysfunction. A controlled prospective 4-year follow-up study. Int J Oral Maxillofac Surg 2000;29:183-7.

12. Nitzan DW, Dolwick MF. Temporomandibular joint fibrous ankylosis following orthognathic surgery: report of eight cases. Int J Adult Orthodon Orthognath Surg 1989;4:7-11.

13. Onizawa K, Schmelzeisen R, Vogt S. Alteration of temporomandibular joint symptoms after orthognathic surgery: comparison with healthy volunteers. J Oral Maxillofac Surg 1995;53:117-21.

14. Mehra P, Wolford LM. The Mitek mini anchor for TMJ disc repositioning: surgical technique and results. Int J Oral Maxillofac Surg 2001;30:497-503.

15. Goncalves JR, Wolford LM, Cassano DS, da Porciuncula G, Paniagua B, Cevidanes LH. Temporomandibular joint condylar changes following maxillomandibular advancement and articular disc repositioning. J Oral Maxillofac Surg 2013;71:1759.e1-15.

16. Kobayashi T, lzumi N, Kojima T, Sakagami N, Saito 1, Saito C. Progressive condylar resorption after mandibular advancement. Br J Oral Maxillofac Surg 2012;50:176-80.

17. Carvalho Fde A, Cevidanes LH, da Motta AT, Almeida MA, Phillips C. Three-dimensional assessment of mandibular advancement 1 year after surgery. Am J Orthod Dentofacial Orthop 2010; 137(4 Suppl):S53.e1-12.

18. Cevidanes LH, Bailey LJ, Tucker GR Jr, Styner MA, Mol A, Phillips CL, et al. Superimposition of 3D cone-beam CT models of orthognathic surgery patients. Dentomaxillofac Radiol 2005; 34:369-75.

19. Paniagua B, Cevidanes L, Walker D, Zhu H, Guo R, Styner M. Clinical application of SPHARM-PDM to quantify temporomandibular joint osteoarthritis. Comput Med lmaging Graph 2011; 35:345-52.

20. Gonçalves JR, Gomes LC, Vianna AP, Rodrigues DB, Goncalves DA, Wolford LM. Airway space changes after maxillomandibular counterclockwise rotation and mandibular advancement with TMJ Concepts ${ }^{\circledR}$ total joint prostheses: three-dimensional assessment. Int J Oral Maxillofac Surg 2013;42:1014-22.

21. Dicker GJ, Tuijt M, Koolstra JH, Van Schijndel RA, Catelijns JA, Tuinzing DB. Static and dynamic loading of mandibular condyles and their positional changes after bilateral sagittal split advancement osteotomies. Int J Oral Maxillofac Surg 2012;41:1131-6.

22. Kim Yl, Jung YH, Cho BH, Kim JR, Kim SS, Son WS, et al. The assessment of the short- and long-term changes in the condylar position following sagittal split ramus osteotomy (SSRO) with rigid fixation. J Oral Rehabil 2010;37:262-70.

23. Will LA, Joondeph DR, Hohl TH, West RA. Condylar position following mandibular advancement: its relationship to relapse. J Oral Maxillofac Surg 1984;42:578-88.

24. Hackney FL, Van Sickels JE, Nummikoski PV. Condylar displacement and temporomandibular joint dysfunction following bilateral sagittal split osteotomy and rigid fixation. J Oral Maxillofac Surg 1989;47:223-7.

25. Hwang SJ, Haers PE, Sailer HF. The role of a posteriorly inclined condylar neck in condylar resorption after orthognathic surgery. J Craniomaxillofac Surg 2000;28:85-90.

26. Mobarak KA, Espeland L, Krogstad 0, Lyberg T. Mandibular advancement surgery in high-angle and low-angle Class 11 patients: different long-term skeletal responses. Am J Orthod Dentofacial Orthop 2001;119:368-81. 